\title{
Estimativa da área da folha da batateira utilizando medidas lineares
}

\author{
Marcelo CC Silva ${ }^{1}$; Paulo Cezar R Fontes²; Rafael G Viana ${ }^{1}$ \\ ${ }^{2}$ UFV - Depto. Fitotecnia, 36571-000 Viçosa-MG; ${ }^{1}$ Pós-graduando, UFV - Depto. Fitotecnia; ${ }^{2}$ Bolsista CNPq; \\ mdecastro70@yahoo.com.br; pacerefo@ufv.br
}

\section{RESUMO}

O objetivo deste experimento foi determinar o modelo mais apropriado para estimar a área da folha da batateira, utilizando-se medidas de comprimento e largura da folha. Foram coletadas 300 folhas de 300 plantas de batata, cultivar Monalisa, de forma aleatória, aos 21 e 56 dias após a emergência (DAE). Em laboratório, foram medidos o comprimento (C), a largura (L) e a área de cada folha (AF). Os dados foram submetidos à análise de regressão com o valor da AF sendo considerado a variável dependente e os valores de comprimento e largura de folha as variáveis independentes. Foram testados três modelos estatísticos: linear, exponencial e logarítmico. AAF da batateira foi mais precisamente estimada $\left(\mathrm{R}^{2}=0,88\right)$, usando as medidas, $\mathrm{L}$ e $\mathrm{C}(\mathrm{AF}=0,2798 * * \mathrm{LC}+71,267)$. Para maior rapidez e praticidade, a AF da batateira, foi também apropriadamente estimada medindo-se apenas $\mathrm{L}$ ou $\mathrm{C}$ da folha e utilizando-se as equações $\mathrm{AF}=0,0479 * * \mathrm{~L}+10,777\left(\mathrm{R}^{2}=0,83\right)$ ou $\mathrm{AF}=0,0659 * * \mathrm{C}+12,979$ $\left(\mathrm{R}^{2}=0,82\right)$. A área foliar estimada $21 \mathrm{DAE}$, utilizando o modelo linear foi de $234,41 \mathrm{~cm}^{2}$, sendo que o valor real medido, foi de 185,52 $\mathrm{cm}^{2}$. Aos $56 \mathrm{DAE}$, a área foliar estimada pelo mesmo modelo foi de $175,60 \mathrm{~cm}^{2}$, o valor real medido, foi de $176,01 \mathrm{~cm}^{2}$. Com um dos modelos propostos, a área da folha pode ser estimada em tempo real, de forma rápida e sem a necessidade de coletar a folha.

\begin{abstract}
Evaluation of the potato plant leaf area using linear measures

The objective of this experiment was to determine the most appropriate model to estimate potato leaf area through the leaf length and width. 300 leaves of 300 potato plants, cv. Monalisa were collected in an aleatory way, 21 and 56 days after the plant emergence (DAE). In laboratory, the length (C), width (L) and area of each leaf (AF) were measured. The data were submitted to the regression analysis with the AF value as a dependent variable and the leaf length and width values as the independent variables. Three statistical models were tested (linear, exponential and logarithmic). Potato plant AF was more precisely estimated $\left(\mathrm{R}^{2}=0,88\right)$, using the two measures, $\mathrm{L}$ and $\mathrm{C}(\mathrm{AF}=0,2798 * * \mathrm{LC}+71,267)$; however, for better speed and workability, potato plant $\mathrm{AF}$, was adequately estimated by measuring leaf $\mathrm{L}$ or $\mathrm{C}$ and using equations $\mathrm{AF}=0,0479 * * \mathrm{~L}+10,777$ $\left(\mathrm{R}^{2}=0,83\right)$ or $\mathrm{AF}=0,0659 * * \mathrm{C}+12,979\left(\mathrm{R}^{2}=0,82\right)$. The evaluated foliar area, $21 \mathrm{DAE}$, using linear model was of $234,41 \mathrm{~cm}^{2}$, and the measured real value, was of $185,52 \mathrm{~cm}^{2}$. At $56 \mathrm{DAE}$, the evaluated foliar area using the linear model was of $175,60 \mathrm{~cm}^{2}$, and the measured real value, was of $176,01 \mathrm{~cm}^{2}$. With one of the proposed models, the potato leaf area can be estimated in real time, quickly and without collecting the leaf.
\end{abstract}

Keywords: Solanum tuberosum L., width, length, statistical models.

Palavras-chave: Solanum tuberosum L., largura, comprimento, modelos estatísticos.

\section{(Recebido para publicação em 23 de janeiro de 2007; aceito em 21 de fevereiro de 2008)}

$\mathrm{F}$ reqüentemente há a necessidade de estimar a área da folha da batata (Solanum tuberosum L.), pois esta característica é importante na avaliação da eficiência fotossintética das plantas (Taiz \& Zeiger, 2004), na determinação de danos bióticos e abióticos (Larcher, 2000), na análise de crescimento (Bianco et al., 2002), relacionado com o acúmulo de matéria seca, metabolismo vegetal, produção final, qualidade e maturação das culturas (Taiz \& Zeiger, 2004). Normalmente é utilizada a técnica destrutiva para medir a área da folha (Bianco et al., 2002).

Os métodos destrutivos ou não, podem ser obtidos diretamente através de aparelhos medidores de área da folha, ou indiretamente pela a área de cobertura vegetal do solo (Andrieu et al., 1997), fotografias digitais (Rodriguez et al., 2000), radiometria (Gordon et al., 1994), relação entre a penetração da radiação e a cobertura vegetal (Watanabe et al.,
1997; Kucharik et al., 1998) ou por dimensões lineares da folha (Schwarz \& Klaring, 2001; Nascimento et al., 2002; Blanco \& Folegatti, 2003).

Em alguns dos métodos é difícil obter as variáveis necessárias para a estimativa da área da folha, exigindo grande demanda de tempo, além da necessidade de utilizar equipamentos caros. $\mathrm{O}$ uso das medidas lineares das folhas, tanto largura quanto comprimento, podem permitir o acompanhamento do crescimento e da expansão foliar da mesma planta, desde o início até o fim do ciclo. Este procedimento pode ser realizado no campo, de forma simples, rápida, fácil e menos onerosa, e tem sido utilizado, para a determinação da área foliar de várias hortaliças, como tomate (Jorge \& Gonzalez, 1997; Schwarz \& Klaring, 2001; Blanco \& Folegatti, 2003), abóbora (Silva et al., 1998), pepino (Blanco \& Folegatti, 2003), inhame (Lu et al., 2004) e berinjela (Aldrighi et al., 2002), não sendo encontradas referências para a estimativa da área da folha da batata.

O objetivo deste trabalho foi determinar o modelo mais apropriado para estimar a área foliar em batata, utilizando-se medidas de comprimento e largura da folha.

\section{MATERIAL E MÉTODOS}

O experimento foi realizado na UFV, em Viçosa, Minas Gerais. A classificação climática do local é do tipo "Cwa”, os dados de irradiação e temperatura (Tabela 1) foram coletados diariamente durante o período experimental. O solo da área experimental é classificado como Podzólico Vermelho-Amarelo Câmbico. O solo foi preparado na forma usual para batata e adubado com 200 $\mathrm{kg} \mathrm{ha}^{-1}$ de sulfato de amônio, $2.000 \mathrm{~kg}$ $\mathrm{ha}^{-1}$ de superfosfato simples, $500 \mathrm{~kg} \mathrm{ha}^{-1}$ de cloreto de potássio, $200 \mathrm{~kg} \mathrm{ha}^{-1}$ de 
Tabela 1. Total semanal de irradiação e temperaturas médias, durante os diversos estádios da batata (total weekly irradiation and average temperatures, during various stadiums of the potato plant). Viçosa, UFV, 2005.

\begin{tabular}{lccc}
\hline Estádio & Semana & Insolação $(\mathbf{h})$ & Temperatura $\left({ }^{\circ} \mathbf{C}\right)$ \\
\hline Emergência & 1 a & 15,4 & 130,2 \\
\hline Vegetativo & 2 a & 25,2 & 118,3 \\
\hline \multirow{2}{*}{ Tuberização } & 3 a & 13,3 & 116,2 \\
\hline & 4 a & 46,2 & 102,9 \\
& 5 a & 25,9 & 109,2 \\
\hline 6 a & 47,6 & 109,9 \\
& 7 a & 30,8 & 119,0 \\
& 8 a & 33,6 & 119,7 \\
Senescência & 9 a & 32,9 & 119,0 \\
& 10 a & 28,00 & 100,8 \\
& 11 a & 60,2 & 95,2 \\
& 12 a & 52,5 & 110,6 \\
& 13 a & 55,3 & 100,1 \\
\hline Total no ciclo & 14 a & 47,6 & 112,0 \\
\hline Média diária & 15 a & 53,2 & 134,4 \\
\hline
\end{tabular}

Tabela 2. Valores máximo, mínimo e médio da largura, comprimento e área da folha da batateira, 21 e 56 dias após a emergência (maximum, minimum and medium values of the width, length and potato leaf area, 21 and 56 days after emergency). UFV, Viçosa, 2005.

\begin{tabular}{lrrrrrrr}
\hline \multirow{2}{*}{ Característica } & \multicolumn{3}{c}{ 21 DAE } & & \multicolumn{3}{c}{ 56 DAE } \\
\cline { 2 - 3 } \cline { 8 - 9 } & Máximo & Mínimo & Médio & & Máximo & Mínimo & Médio \\
\hline Largura $(\mathrm{cm})$ & 24,67 & 14,92 & 19,66 & & 23,00 & 15,83 & 19,46 \\
Comprimento $(\mathrm{cm})$ & 36,28 & 21,36 & 29,66 & & 30,04 & 19,67 & 24,58 \\
Área da folha $\left(\mathrm{cm}^{2}\right)$ & 276,74 & 101,90 & 185,52 & & 266,75 & 102,03 & 176,01 \\
\hline
\end{tabular}

DAE: Dias após a emergência.

sulfato de magnésio, $10 \mathrm{~kg} \mathrm{ha}^{-1}$ de bórax, $10 \mathrm{~kg} \mathrm{ha}^{-1}$ de sulfato de zinco, $10 \mathrm{~kg} \mathrm{ha}^{-1}$ de sulfato de cobre e $250 \mathrm{~g} \mathrm{ha}^{-1}$ de molibdato de sódio. O plantio foi realizado em 15/05/05, em espaçamento de 75 x 25 cm, utilizando-se tubérculos-semente da cv. Monalisa, de tamanho uniforme e brotados. As práticas culturais e irrigação por aspersão foram as recomendadas para a cultura (Fontes, 2005).

Foi utilizado o delineamento experimental em blocos completamente casualizados, com seis repetições. Foram utilizadas 300 folhas completas em 300 plantas de batata competitivas e livres de pragas. As folhas foram tomadas de forma aleatória, 21 dias após a emergência (DAE) e próximo a senescência das folhas (56 DAE). Em laboratório as folhas foram submetidas às medidas de comprimento $(\mathrm{C})$ e a largura (L), avaliadas individualmente, utilizando uma régua graduada em milímetros. O comprimento correspondeu à distância entre a base distal do pecíolo e extremidade do folíolo terminal, assim como a largura à distância do limbo entre os dois maiores folíolos adjacentes. Também foi determinada a área de cada folha (AF), utilizando um integrador de área foliar modelo LI-3000.

Os dados obtidos foram submetidos à análise de regressão. O valor da área da folha foi considerado como variável dependente e, os comprimentos e, larguras as variáveis independentes. Foram utilizados os aplicativos SAS e SAEG. Para o ajuste dos dados os modelos estatísticos linear, exponencial e logarítmico foram selecionados para serem testados. Os modelos foram avaliados com base nos critérios: lógica biológica, significância do quadrado médio do resíduo da regressão, não significância do F ou falta de ajustamento, alto valor do coeficiente de determinação $\left(\mathrm{R}^{2}\right)$ a $5 \%$ de probabilidade segundo Silva et al. (2007). Também foram consideradas as significâncias dos parâmetros da regressão, utilizando-se os testes $\mathrm{t}$ e $\mathrm{F}$ a $5 \%$ de probabilidade (Gomes, 2000).

\section{RESULTADOS E DISCUSSÃO}

Os valores médios de comprimento e largura das folhas, nas duas épocas foram próximos, indicando que no período compreendido entre as duas coletas as folhas estavam em completo desenvolvimento (Tabela 2). Embora os dados climáticos de insolação e temperatura acumuladas na semana da época de coleta, $3^{\mathrm{a}}$ e $8^{\mathrm{a}}$ semana após a emergência, diferissem, principalmente para insolação (Tabela 1). As plantas não apresentaram folhas com área inferior a $100 \mathrm{~cm}^{2}$. A maioria das folhas (40 e 42\% para aquelas coletadas 21 e 56 dias após a emergência (DAE) respectivamente) apresentou AF na faixa de $151-200 \mathrm{~cm}^{2}$, caracterizando uma distribuição normal de área foliar, concordando com Bianco et al. (2002), em trabalho com estimativa de área da folha de parreira brava através de medidas lineares. A distribuição normal tem formato de sino, com valores tendendo a + ou - infinito, a média populacional indica a posição central da distribuição, os dados são aproximadamente simétricos (Gomes, 2000), indicando que os dados de área foliar, largura e comprimento estão em conformidade com a estatística.

$\mathrm{Na}$ avaliação feita aos 21 DAE, o modelo linear utilizando o produto do comprimento pela largura foi o mais preciso para estimar a AF, apresentando o maior coeficiente de determinação $\left(\mathrm{R}^{2}=0,88\right)$ e a menor soma de quadrado dos resíduos $(\mathrm{SQR}=254,20)$ para todas as características de medida, quando comparado com os demais modelos ajustados (Figura 1; Tabela 3). A área foliar estimada $21 \mathrm{DAE}$, utilizando este modelo foi de $234,41 \mathrm{~cm}^{2}$, sendo que o valor real medido, foi de $185,52 \mathrm{~cm}^{2}$ (Tabela 2). Já na avaliação feita aos 56 DAE, o modelo linear utilizando o quadrado do produto do comprimento pela largura foi o mais recomendado para 
Tabela 3. Medidas avaliadas aos 21 e 56 dias após a emergência, modelos estatísticos, coeficientes de determinação ( $\mathrm{R}^{2}$ ), somas dos quadrados do resíduo (SQR) e equações ajustadas para as estimativas das áreas das folhas (AF) em função do comprimento (C) e da largura (L) da folha da batateira (appraised measures on 21 and 56 days after emergency, statistical models, determination coefficients ( $\left.\mathrm{R}^{2}\right)$, sums of residue squares (SQR) and adjusted equations for the estimates of leaf areas (AF) in function of the length (C) and of the width (L) of the potato leaves). UFV, Viçosa, 2005.

\begin{tabular}{|c|c|c|c|c|}
\hline \multicolumn{5}{|c|}{ Medição ao 21 DAE } \\
\hline Característica & Modelo estatístico & $\mathbf{R}^{2}$ & SQR & Equação estimada \\
\hline Comprimento & Exponencial & 0,79 & 416,760 & $\mathrm{AF}=27,102$ e $0,0639^{* *} \mathrm{C}$ \\
\hline Largura & & 0,82 & 361,913 & $A F=28,189$ e $0,0944^{* *} L$ \\
\hline LarguraxComprimento & & 0,85 & 292,261 & $A F=66,392$ e $0,0017^{* *} L C$ \\
\hline 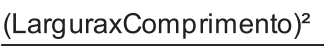 & & 0,84 & 311,596 & $A F=109,69$ e $1 \mathrm{E}-06^{* *}(\mathrm{LC})$ \\
\hline Comprimento & Logarítmico & 0,77 & 455,946 & $A F=334,94 L^{* *}(C)-947,72$ \\
\hline Largura & & 0,82 & 366,177 & $A F=338,36 L n^{* *}(L)-819,98$ \\
\hline LarguraxComprimento & & 0,85 & 307,909 & $A F=178,96 \operatorname{Ln}^{* *}(L C)-951,77$ \\
\hline${\text { (LarguraxComprimento })^{2}}^{2}$ & & 0,84 & 359,812 & $\mathrm{AF}=89,48 \mathrm{Ln}^{* *}(\mathrm{LC}) 2-951,77$ \\
\hline \multicolumn{5}{|c|}{ Medição aos 56 DAE } \\
\hline Comprimento & Exponencial & 0,82 & 234,768 & $\mathrm{AF}=29,84$ e $0,0714^{* *} \mathrm{C}$ \\
\hline Largura & & 0,73 & 362,066 & $A F=22,438$ e $0,1048^{* *} L$ \\
\hline LarguraxComprimento & & 0,84 & 205,285 & $A F=61,705$ e $0,0021^{* *} L C$ \\
\hline${\text { (LarguraxComprimento })^{2}}^{2}$ & & 0,85 & 204,024 & $\mathrm{AF}=102,47$ e $2 \mathrm{E}-06^{* *}(\mathrm{LC})$ \\
\hline Comprimento & Logarítmico & 0,80 & 252,581 & $A F=299,39 L n^{*}(C)-780,96$ \\
\hline Largura & & 0,71 & 368,256 & $A F=349,62 L n^{* *}(L)-860,8$ \\
\hline LarguraxComprimento & & 0,82 & 228,972 & $A F=173,67 L^{* *}(L C)-894,05$ \\
\hline (LarguraxComprimento) $^{2}$ & & 0,83 & 232,973 & $\mathrm{AF}=86,835 \mathrm{Ln}^{* *}(\mathrm{LC}) 2-894,05$ \\
\hline
\end{tabular}

** Significativos ao nível de 5\% de probabilidade pelo teste t.
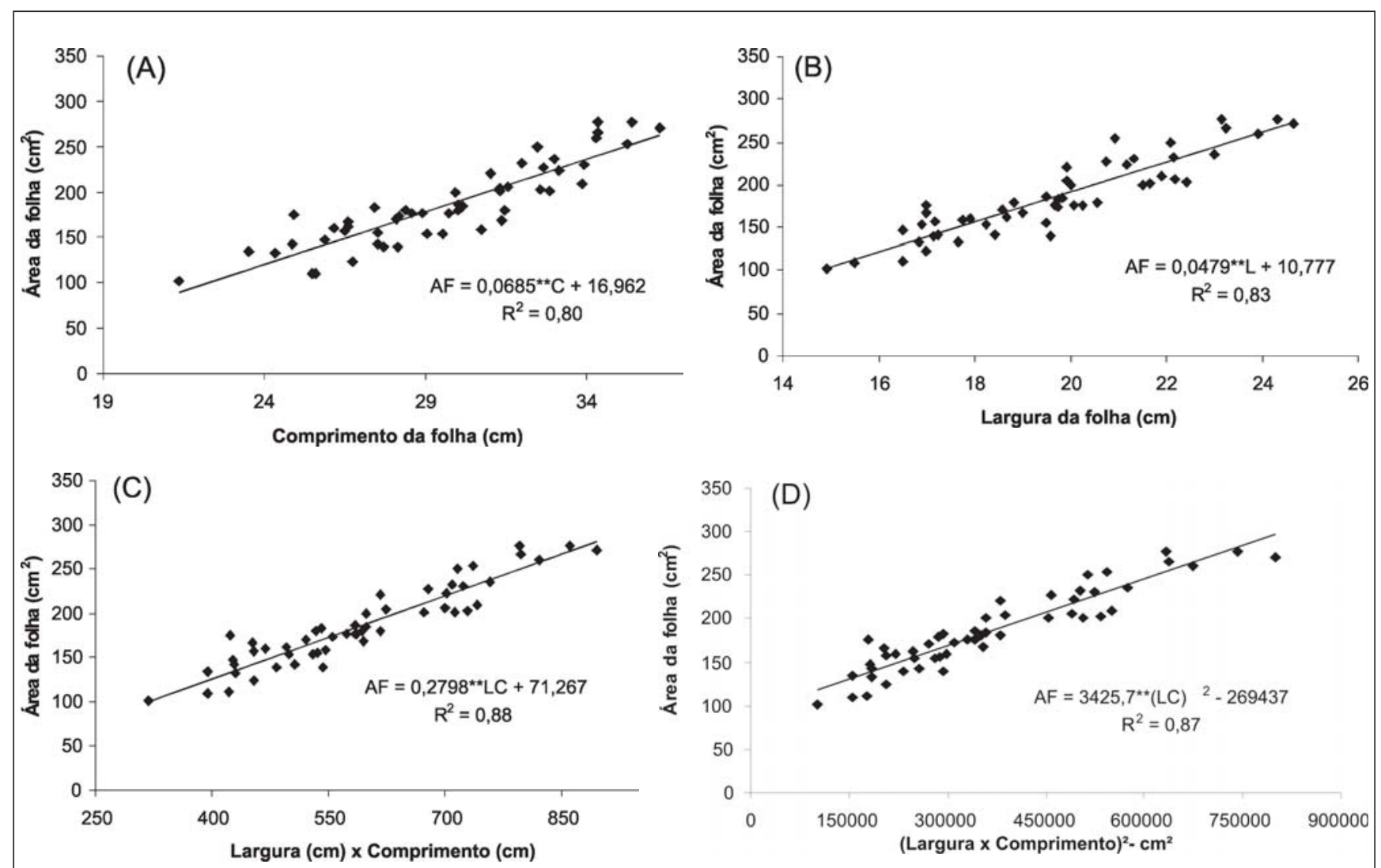

Figura 1. Relação entre comprimento (A), largura (B), comprimento x largura (C) e comprimento x largura ao quadrado (D) e área da folha da batateira, aos 21 dias após a emergência (relationship among length (THE), width (B), length $\mathrm{x}$ width (C) and length $\mathrm{x}$ width to the square (D) and area of the potato leaf plant, 21 days after the emergency). UFV, Viçosa, 2005. 


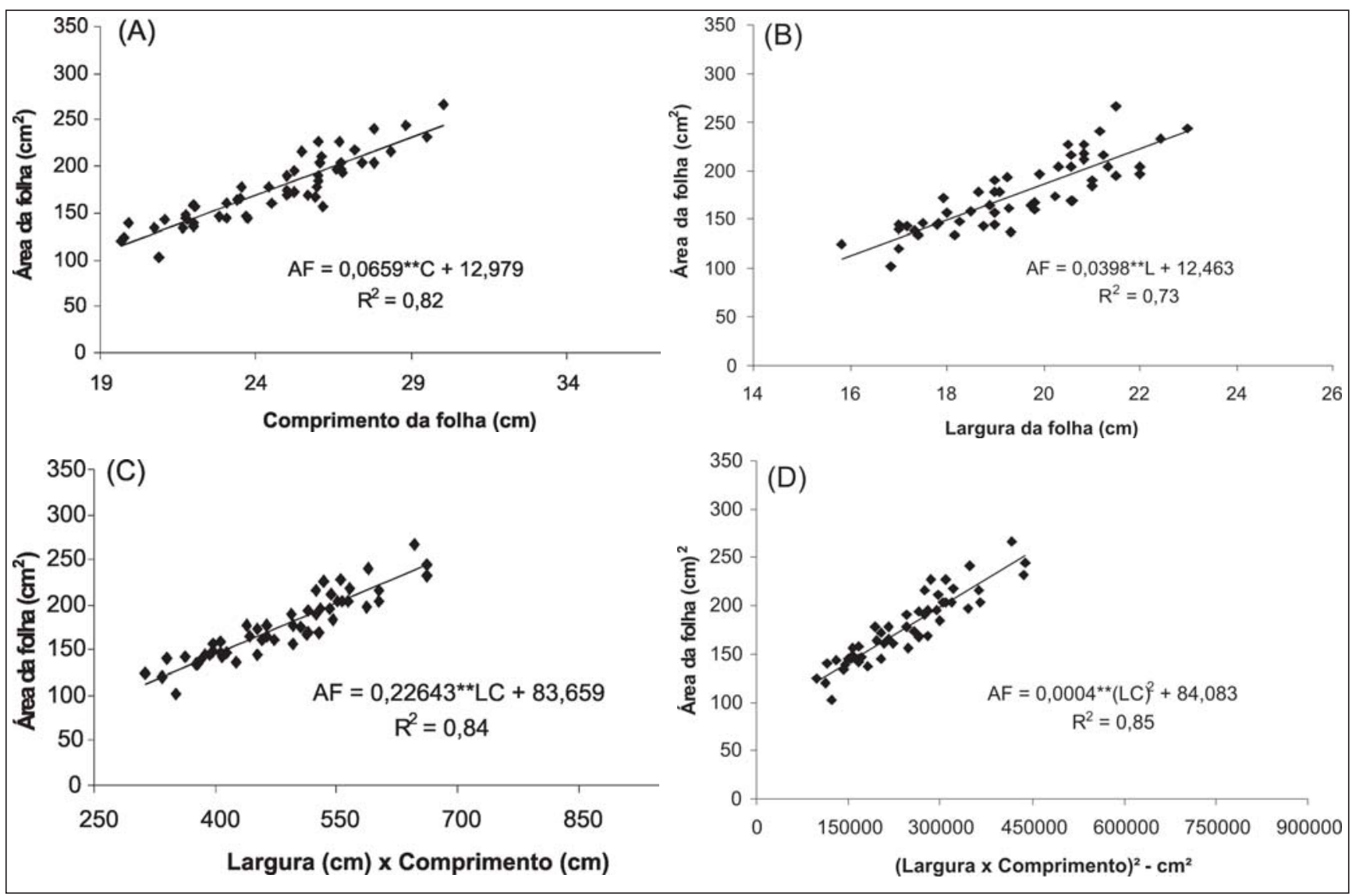

Figura 2. Relação entre comprimento (A), largura (B), comprimento x largura (C) e comprimento x largura ao quadrado (D) e área da folha da batateira, aos 56 dias após a emergência (relationship among length (THE), width (B), length x width (C) and length $\mathrm{x}$ width to the square (D) and potato leaf area, 56 days after the emergency). UFV, Viçosa, 2005.

estimar a AF, obtendo o maior $\mathrm{R}^{2}(0,85)$ e a menor SQR $(200,00)$ (Figura 2; Tabela 3). Aos 56 DAE, a área foliar estimada por este modelo foi de $175,60 \mathrm{~cm}^{2}$, o valor real medido, foi de $176,01 \mathrm{~cm}^{2}$ (Tabela 2). Lu et al. (2004), trabalhando com taro, concluíram que o modelo que inclui comprimento $\mathrm{x}$ largura de folha proporcionou maior consistência na estimativa da área foliar ao longo do desenvolvimento da folha de cultivares de taro do que modelos com apenas uma medida. O uso de modelo com uma variável evita problema da co-linearidade entre comprimento e largura da folha (Williams \& Martinson, 2003), além de exigir apenas uma medição linear. A estimativa mais precisa da área da folha do meloeiro, utilizando-se a largura da folha ao invés do comprimento, pode ser devido à maior estabilidade e menores erros na sua medida (Nascimento et al., 2002). Porém, Schwarz \& Klaring (2001) não aconselham a medição da largura da folha do tomateiro, pois é mais difícil e demanda tempo quando relacionada com a medição do comprimento devido à necessidade do alinhamento dos folíolos, mesmo percebendo que há maior precisão na estimativa da área da folha usando a medida de largura.

Similarmente ao ocorrido com o modelo linear, a equação com o produto da largura pelo comprimento da folha proporcionou o maior valor de $\mathrm{R}^{2}(0,85)$ e o menor valor de SQR, para os modelos exponencial e logarítmico (Tabela 3).

Verifica-se que os modelos $\mathrm{AF}=$ $0,0479 * * \mathrm{~L}+10,777$ e $\mathrm{AF}=0,0659 * * \mathrm{C}$ +12,979, também permitiram adequada estimativa de AF da batateira aos 21 e 56 DAE, respectivamente, com reduzida perda de precisão (Figuras 1 e 2), visto que podem utilizar apenas uma medida da área foliar. Porém, quando medimos apenas uma variável, corremos o risco de obtermos apenas um erro e economizarmos tempo. Dessa maneira, o técnico pode estimar a área foliar de forma prática, rápida e sem necessidade de coletar a folha.
Aos 56 DAE, os resultados foram semelhantes aos obtidos aos $21 \mathrm{DAE}$ (Figuras 1 e 2), apesar dos valores obtidos para $\mathrm{x}$ e y terem sido um pouco menores (Tabela 2). Entretanto, quando os modelos linear e exponencial se equivalem, como verificados na Tabela 3, é bem mais fácil trabalharmos com o primeiro, pois a equação é simples.

Valores semelhantes de $\mathrm{R}^{2}$ (Figura 2) foram encontrados por Jorge \& Gonzalez, 1997; Astegiano, 2001; Schwarz \& Klaring, 2001; Blanco \& Folegatti, 2003, todos trabalhando com tomate; o valor de $\mathrm{R}^{2}$ nestes trabalhos foi superior a 0,70 , o que indica que a variabilidade total existente na área da folha, acima de $70 \%$ podem ser explicadas pela análise de regressão.

Independente do modelo estatístico, linear, exponencial ou logarítmico, a área da folha (AF) da batateira 21 e 56 dias após a emergência foi mais precisamente estimada usando o produto das medidas de largura (L) e comprimento (C) da folha $\left(\mathrm{AF}=0,2798^{* *} \mathrm{LC}+71,267\right)$. 


\section{AGRADECIMENTOS}

À FAPEMIG pelo apoio financeiro e ao CNPq pelas bolsas de Pós-graduação e de Produtividade em Pesquisa concedidas aos autores.

\section{REFERÊNCIAS}

ALDRIGHI CB; DUARTE GB; DEIBLER A; PAULA VA; FERNANDES HS; MARTINS SR; MENDES MEG. 2002. Estimativa da área foliar em plantas de berinjela por métodos não destrutivos. Horticultura Brasileira 20: 2. Suplemento.

ANDRIEU B; ALLIRAND JM; JAGGARD K. 1997. Ground cover and leaf area index of maize and sugar beet crops. Agronomie 17: 315-321.

ASTEGIANO ED; FAVARO JC; BOUZO CA. 2001. Estimación del área foliar em distintos cultivares de tomate (Lycopersicon esculentum Mill.) utilizando medidas foliares lineales. Investigation agrícola 16: 245-256.

BLANCO FF; FOLEGATTI MV. 2003. A new method for estimating the leaf area index of cucumber and tomato plants. Horticultura Brasileira 21: 666-669.
BIANCO S; PITELLI RA; CARVALHO LB. 2002. Estimativa da área foliar de Cissampelos glaberrima usando dimensões lineares do limbo foliar. Planta Daninha 20: 353-356.

FONTES PCR. 2005. Olericultura: teoria e prática. Viçosa: Universidade Federal de Viçosa. 486p.

GOMES PF. 2000. Curso de estatística experimental. Piracicaba: São Paulo. 477p.

GORDON R; BROWN DM; DIXON M. 1994. Non-destructive estimation of potato leaf area index using a fish-eye radiometer. Potato Research 37: 393-402.

JORGE Y; GONZÁLEZ F. 1997. Estimación de área foliar em los cultivos de ají y tomate. Agrotecnica de Cuba 27: 123-130.

KUCHARIK CJ; NORMAN JM; GROWER ST. 1998. Measurement of branch area and adjusting leaf area index indirect measurement. Agriculture Forest Meteorology 91: 69-88.

LARCHER, W. 2000. Ecofisiologia vegetal. Rima. 531p.

LU HY; LU CT; WEI ML; CHA LF. 2004. Comparison of different models for nondestructive leaf area estimation in taro. Agronomy Journal 96: 448-453.

NASCIMENTO IB; FARIAS CH; SILVA MCC; MEDEIROS JF; SOBRINHO JE; NEGREIROS MZ. 2002. Estimativa da área foliar do meloeiro. Horticultura Brasileira 20: 555-558.
RODRÍGUEZ A; CASA, AC; BRESSANINI L; ACCIETTO R; OVANDO G. 2000. Determinación del área foliar en papa (Solanum tuberosum L., var. Spunta) por medio de fotografías digitales conociendo la relación entre el número de píxeles y la altura de adquisición. Revista Brasileira de Agrometeorologia 8: 215-221.

SCHWARZ D; KLARING H. 2001. Allometry to estimate leaf area tomato. Journal of Plant Nutrition 24: 1291-1309.

SILVA NF; FERREIRA FA; FONTES PCR; CARDOSO AA. 1998. Modelos para estimar a área foliar de abóbora por meio de medidas lineares. Revista Ceres 45: 287-291.

SILVA MCC; FONTES PCR; MIRANDA GV. 2007. Modelos estatísticos para descrever a produtividade de batata em função da adubação nitrogenada. Horticultura Brasileira 25: 360-364.

TAIZ L; ZEIGER E. 2004. Fisiologia vegetal. Porto Alegre: Artmed. 719p.

WATANABE J; POOL RM; WATANABE KN. 1997. The evaluation of an optical method to estimate the leaf area of grapevines. Journal of the Japanese Society Horticultural Science 66: 235-244.

WILLIAMS L; MARTINSON TE. 2003. Nondestructive leaf area estimation of 'Niagara' and 'De Chaunac' grapevines. Scientia Horticulture 98: 493-498. 